\title{
A IMPORTÂNCIA DO PLANO DE NEGÓCIOS PARA UMA GESTÃO MAIS EFICIENTE
}

\section{ARTIGO ORIGINAL}

MORAES, Ithaúna Albuquerque Martins ${ }^{1}$

MORAES, Raimundo Nonato de ${ }^{2}$

MORAES, Ithaúna Albuquerque Martins. MORAES, Raimundo Nonato de. A importância do plano de negócios para uma gestão mais eficiente. Revista Científica Multidisciplinar Núcleo do Conhecimento. Ano 05, Ed. 06, Vol. 04, pp. $172-$ 181. Junho de 2020. ISSN: 2448-0959, Link de acesso: https://www.nucleodoconhecimento.com.br/administracao/plano-de$\underline{\text { negocios }}$

\section{RESUMO}

Demanda-se, dos indivíduos, algumas habilidades quando esses desejam se tornar empreendedores, tai como o planejamento, a formação de equipes, a liderança, a capacidade de negociação e resolução de problemas etc. Esse artigo apresenta uma revisão da literatura sobre o plano de negócios, de marketing e financeiro, entendidos como essenciais à uma gestão eficiente. Entende-se o plano de negócios como uma ferramenta que auxilia o planejamento estratégico de uma empresa. Trata-se de um instrumento dinâmico e fundamental para uma gestão eficiente. A relevância do plano de negócios se dá em razão de que ele envolve etapas voltadas à captação, elaboração e bom senso ao se avaliar um conjunto de fatores tangentes à viabilidade financeira e mercadológica que possibilitarão, ao empreendedor, a coordenação de

\footnotetext{
${ }^{1}$ Pós-Graduação em Gestão de Projetos e graduado em Administração. ${ }^{2}$ Mestre.
} 
um plano de ação de forma mais eficiente, sendo necessário, então, para a manutenção dessa empresa, o que justifica esse estudo.

Palavras-chave: Planejamento financeiro, marketing, plano de negócios.

\section{INTRODUÇÃO}

As mudanças no mundo corporativo, em razão do fluxo intenso e diário de novas informações e possibilidades, têm levado as empresas a enfrentarem desafios ao buscarem por uma performance mais eficiente (PINTO et al, 2017; SANTOS; PINHEIRO, 2017; MANNA, 2011; QUADROS, 2004). Rocha (2009) afirma que as empresas devem compreender que é por meio da percepção de oportunidades que essa performance poderá ser potencializada. É fundamental para se sobreviver nesse cenário que é marcado pela competitividade. Assim sendo, tanto para dar início a um negócio ou para realizar a sua manutenção é preciso que os responsáveis dominem os conceitos de gestão e planejamento, e, mais do que isso, esses elementos precisam ser primordiais no processo de tomada de decisão. Nesse sentido, para que um negócio se torne bem sucedido o planejamento é indispensável.

A atualização das informações empresariais, em termos estratégicos, táticos e operacionais, é essencial e tem se revelado cada vez mais como uma vantagem competitiva. Nesse contexto, o aperfeiçoamento profissional, segundo Santos e Pinheiro (2017), tornou-se significativo para a sobrevivência das empresas, pois é a partir dele que as organizações se tornam mais eficientes e aptas a competir no mercado, que, como ressaltado, torna-se cada vez mais competitivo. Assim sendo, ao idealizar um negócio, entende-se que o empreendedor deve buscar e adquirir conhecimento sobre o nicho mercadológico que pretende atuar (como, por exemplo, o ramo da educação, que é um mercado que tem aumentado de forma exponencial). É preciso, ainda, que os responsáveis por conduzir o negócio percebam as possíveis dificuldades que podem vir a seguir.

É nesse sentido que o plano de negócios se revela como um importante instrumento. Nele, conforme Santos e Pinheiro (2017), o modelo de negócio é representado, tendo- 
se como escopo a minimização de erros e, ainda, o aumento das possibilidades de sucesso no setor desejado (como a educação). Deve-se frisar que o ato de planejar se relaciona com a determinação antecipada de objetivos almejados pela organização, e, assim, é necessário observar os recursos que serão utilizados para chegar a esses objetivos. O planejamento assume um papel de suma importância nesse processo, pois tendo-se o plano de negócios definido, é possível visualizar até onde a empresa quer chegar e, ainda, de que forma chegará e o que fará para chegar. Chiavenato (2007) frisa que o planejamento estratégico é um conjunto sistematizado voltado à tomada de decisões acerca de um dado empreendimento.

Destarte, essas decisões afetam toda a empresa durante um longo período (PINTO et al, 2017; SANTOS; PINHEIRO, 2017; MANNA, 2011; QUADROS, 2004). Assim sendo, a tomada de decisão apoiada no planejamento direciona os gestores para que assumam caminhos capazes de tornar o seu negócio sustentável e inovador. Cabe auferir, então, que o plano de negócios exerce um papel sumário na organização, pois, a partir dele, a empresa pode organizar as suas ideias, realizar um planejamento de forma rica, clara e detalhada e reduzir o risco de fracasso antes mesmo de iniciar as atividades ou expandir um empreendimento já existente. É, ainda, uma fase importante, pois é o plano de negócios que viabiliza a integração de diversos conhecimentos e técnicas de áreas distintas da empresa, sendo possível, então, ter uma percepção da entidade como um todo para, após, estruturar o negócio.

\section{O PLANO DE NEGÓCIOS}

O plano de negócios atua como um norteador para que a empresa consiga alcançar os objetivos almejados, e, dessa forma, a análise oferecida por ele faz com que o gestor consiga ter uma percepção mais clara sobre até onde deve ir e como chegar nesse lugar. Assim, o plano de negócios assume um papel primordial no planejamento estratégico, visto que é empregado como uma ferramenta capaz de orientar o gestor no processo de implantação ou manutenção do negócio, e, dessa forma, esse plano pode apontar parcerias em potencial, esclarecer objetivos, definir metas e acompanhar o crescimento da organização de forma geral (SANTOS; PINHEIRO, 2017). Zimmerman (2012) reitera que o plano de negócios tem como escopo mapear 
os riscos, e, também, é responsável por calcular o retorno do investimento realizado de forma clara e objetiva.

Bernardi (2008), por sua vez, alude que, quando bem elaborado, potencializa o sucesso do negócio em questão (aqui representado pelo escola particular). Para Dornelas (2007), o resultado poderá ser satisfatório quando são realizadas pesquisas acerca do ramo em que se deseja atuar ou atua. A partir dessa pesquisa é possível compreender, em detalhes, o cenário em que se deseja atuar. Conhecer os concorrentes e calcular os investimentos são etapas cruciais para que o modelo de negócio tenha sucesso. Bernardi (2008) frisa, também, que todos os que desejam empreender ou que já possuem um negócio obterão vantagem competitiva com a elaboração de um plano de negócios, pois evita-se as chances de falência em razão de uma má administração. O SEBRAE (2013), por sua vez, compreende o plano de negócios como um documento que descreve os objetivos que sustentam um negócio.

Santos e Pinheiro (2017) compreendem que esse documento apresenta os caminhos a serem percorridos para que esses objetivos sejam mantidos e o foco não se perca, reduzindo-se, dessa forma, os possíveis riscos. O plano de negócios permite, ainda, que sejam identificados, de forma clara e precisa, os erros potenciais ainda na fase da maturação da ideia. Chiavenato (2005), por sua vez, elucida que o planejamento produz um efeito imediato que é o plano. Entende, ainda, que todos os planos têm um objetivo em comum: a previsão, programação e a coordenação de uma sequência lógica de acontecimentos, e, caso bem sucedidos, conduzirão esse negócio ao alcance dos objetivos almejados. Ele ajuda, ainda, o gestor a concluir se a sua ideia é viável e a procurar por informações mais consistentes relacionadas ao ramo, aos produtos e aos serviços que se pretende oferecer.

Apresenta-se, ainda, dados sobre clientes, concorrentes, fornecedores e pontos fortes e fracos do negócio. Dessa forma, ao final, o plano irá demonstrar os custos e as despesas do negócio, o investimento inicial, os recursos necessários para colocar a empresa em operação, as estratégias empregadas para o crescimento da empresa, o marketing e a projeção da receita e lucro para os próximos anos (PINTO et al, 2017; SANTOS; PINHEIRO, 2017; MANNA, 2011; QUADROS, 2004). Analisar se vale à 
pena abrir, manter ou ampliar o negócio é essencial, e, para tanto, deve-se considerar as informações oferecidas pelo plano de negócios. Assim sendo, embora a o plano de negócios não seja uma garantia do sucesso empresarial, conforme Santos e Pinheiro (2017), ele permite um processo de tomada de decisões mais eficiente, o que amplia as chances de sucesso.

Por se tratar de uma descrição do negócio, viabiliza, então, melhores negociações e respostas aos questionamentos dos fornecedores, distribuidores, bancos, sócios, e, ainda, do próprio empreendedor e de sua equipe (SANTOS; PINHEIRO, 2017). Ele atua, dessa forma, como a base que fomenta as atividades empresariais, e, assim, formaliza, no papel, as ideias criativas do empreendedor, essenciais ao atendimento das demandas do público da empresa em questão (aqui representadas pelo alunado e os seus familiares). O produto ou serviço ofertado deve, então, suprir tais necessidades. Uma vez que o mercado muda constantemente, observa-se que as novas oportunidades surgem em razão desse contexto marcado pelas mudanças mássicas e contínuas. As ameaças são inevitáveis, e, nesse contexto, o plano deve ser elaborado levando em consideração características locais.

Dessa forma, cabe auferir que o plano de negócios tem como característica, de acordo com Santos e Pinheiro (2017), a fácil adaptação à realidade da empresa em questão, e, assim, pode ser corrigido ou aperfeiçoado sempre que o gestor julgar como pertinente. Nesse sentido, o plano de negócios atua como uma das ferramentais mais primordiais para que um empreendimento tenha uma boa performance em seu nicho de mercado. Assim sendo, os autores recomendam que ele seja escrito á lápis, pois o ideal é que novos ajustes sejam feitos de modo contínuo, visto o cenário marcado por mudanças diárias e contínuas. Os gestores, em muitas das vezes, precisam recorrer aos consultores para identificar e corrigir erros, que podem fomentar a falta de crescimento ou crise da empresa. O planejamento, nesse contexto, pode minimizar os inibidores dos resultados e maximizar os facilitadores no processo de tomada de decisão, uma vez que elas se tornam mais assertivas. 


\section{O PLANO DE MARKETING E A DINAMIZAÇÃO DA GESTÃO}

Conforme Kotler (1998), o planejamento de marketing trata-se da habilidade de antever as tomadas de decisões referentes ao mercado relacionado à empresa, o seu posicionamento, o desenvolvimento de novos produtos, a definição do preço, os canais de distribuição, as formas de comunicação e os meios para a sua promoção (FORSTER, 2017; MANGINI et al, 2018; SILVA; MAZZON, 2016). O planejamento de marketing é comumente usado para a segmentação de mercados, para identificar o posicionamento, prever o tamanho do mercado e para que seja possível participar de forma viável no segmento de mercado que se deseja atuar. Dessa forma, embora o planejamento de marketing seja um processo simples de compreender, é uma atividade multifacetada, complexa e transfuncional, uma vez que o seu alcance atinge e a todos os níveis que integram uma organização.

O plano de marketing, por sua vez, atua como uma ferramenta de gestão que, na forma de documento, propõe e viabiliza a execução de um plano voltado à comercialização de produtos e serviços. Esse plano pode ser usado como um documento formal ou informal, e, assim, há certa flexibilidade. Nesse sentido, um plano de marketing pode ser aplicado em diversas circunstâncias, como, por exemplo, para introduzir um novo produto no mercado, para renovar a abordagem do mercado para produtos existentes ou, ainda, para agrupar um conjunto de planos departamentais a serem incluídos no planejamento corporativo de uma empresa (FORSTER, 2017). Assim sendo, cabe auferir, também, que um plano de marketing em sua forma mais simples deve conter detalhes importantes sobre a concorrência, incluindo as suas vantagens, desvantagens, potencialidades e fragilidades.

Deve-se analisar, ainda, os sucessos e fracassos, bem como as potencialidades e fragilidades da própria empresa. Forster (2017) alude que há diferentes propostas que versam sobre a estrutura do plano de marketing. Aponta alguns elementos indispensáveis, como o sumário executivo, a análise situacional, a matriz FOFA ou SWOT, a formulação de metas e objetivos, a definição de estratégias e modelos para implementação e o controle das ações. Kotler e Armstrong (2008) apontam que o ambiente de marketing é formado por um microambiente e por um macroambiente. $\mathrm{O}$ 
primeiro é formado pelos agentes próximos à empresas e que podem afetar a sua capacidade de atenção aos clientes (a própria empresa, os fornecedores, intermediários de marketing, mercado de clientes e concorrentes). O macroambiente abrange as forças tecnológicas, políticas, culturais etc.

\section{O PLANO FINANCEIRO COMO BASE PARA A ORGANIZAÇÃO}

O plano financeiro, para que seja eficaz, deve apresentar as diferentes propostas de investimento ligadas às várias atividades operacionais que sustentam uma empresa, e, dessa forma, as opões de financiamento disponíveis devem ser consideradas (LUCION, 2005; LEAL; NASCIMENTO, 2011; OLIVEIRA, 2012). Paralelamente, o planejamento financeiro contribui, também, no sentido de que ajuda a empresa desenvolver, analisar e comparar os muitos cenários a partir de óticas diferentes. Isso permite que as questões relativas às linhas futuras de negócios da empresa, bem como os esquemas de financiamento, se necessários, sejam alinhados. Nesse contexto, o planejamento financeiro formaliza o modo a ser empregado para se chegar aos objetivos financeiros, e, assim, de forma sintetizada, esse plano declara o que a empresa precisará realizar no futuro.

O planejamento financeiro é um dos aspectos importantes para funcionamento e sustentação de uma empresa, pois fornece roteiros para dirigir, coordenar e controlar suas ações na consecução de seus objetivos. Dois aspectos-chave do planejamento financeiro são o planejamento de caixa e de lucros. O primeiro envolve o planejamento do orçamento de caixa da empresa; por sua vez, o planejamento de lucros é normalmente realizado por meio de demonstrativos financeiros projetados, os quais são úteis para fins de planejamento financeiro interno, como também comumente exigidos pelos credores atuais e futuros (GITMAN, 1997 apud LUCION, 2005, p. 145).

Dessa forma, cabe auferir que o planejamento fornece a empresa subsídios para que não seja surpreendida e possa ter uma alternativa já prevista, caso tenha que tomar uma decisão (LUCION, 2005). Nesse contexto, um bom planejamento financeiro deve 
prever o que acontecerá caso o almejado seja inviabilizado, e, assim, o objetivo dele é evitar surpresas e desenvolver e fomentar planos alternativos. Ele engloba uma série de ações, como as projeções de vendas, a renda, os ativos baseados em estratégias alternativas de produção e de marketing, e, ainda, o plano financeiro incorpora a forma pela qual a empresa atende às necessidades e demandas financeiras previstas (LUCION, 2005; LEAL; NASCIMENTO, 2011; OLIVEIRA, 2012). Nesse sentido, uma empresa deve visar a criação e obtenção de valor, porém, uma maior taxa de retorno do capital, a participação do mercado, a obtenção de recursos financeiros devem ser igualmente considerados.

O planejamento financeiro direciona a empresa e estabelece o modo pelo qual os objetivos financeiros podem ser alcançados. Um plano financeiro é, portanto, uma declaração do que deve ser feito no futuro. Em sua maioria, as decisões numa empresa demoram bastante para serem implantadas. Numa situação de incerteza, isso exige que as decisões sejam analisadas com grande antecedência (LEMES, 2002 apud LUCION, 2005, p. 146).

Destarte, um bom planejamento financeiro viabiliza e garante que os objetivos e planos traçados pela organização em relação às operações a serem desempenhadas pelos vários setores da empresa sejam viáveis e internamente coerentes. Nesse sentido, o planejamento financeiro auxilia na estipulação de metas, o que deixa os gestores mais motivados, e, ainda, oferecem mecanismos necessários à avaliação dos resultados. Cabe destacar, também, que planejamento e controle estão intimamente ligados. O planejamento é necessário para a fixação de padrões e metas e o controle, por sua vez, fomenta a obtenção de informações para, posteriormente, realizar a comparação dos planos com os desempenhos reais, fornecendo, dessa forma, meios para que um processo de feedback seja possível, e, para tanto, deve-se explicitar as ligações entre as propostas de investimentos das várias atividades operacionais da empresa e as suas opções de financiamento (LUCION, 2005).

Nesse sentido, caso a empresa esteja pensando em expandir, e, assim, realizar novos investimentos e projetos, precisará, então, de financiamento para que possam ser 
custeados, e, assim, a não percepção da ligação entre o crescimento das vendas com as necessidades de produção pode acarretar o desastre financeiro (LUCION, 2005; LEAL; NASCIMENTO, 2011; OLIVEIRA, 2012). Pode-se reiterar, dessa forma, que o planejamento financeiro compreende a programação avançada de todos os planos que envolvem a administração financeira, e, ainda, a integração e coordenação desses planos com os planos operacionais da empresa em sua totalidade. Assim sendo, ele deve ser realizado e desenvolvido em duas etapas, isto é, à curto e longo prazo, e, para tanto, deve-se acompanhar a execução do planejamento financeiro global a partir da investigação das variações orçamentárias, e, assim, as principais corresponderão a previsão de vendas e ao orçamento de caixa.

\section{CONSIDERAÇÕES FINAIS}

A partir dessa reflexão, pode-se concluir que o planejamento financeiro é um condição para que se chegue ao sucesso empresarial desejado, e, dessa forma, demanda-se profissionais que estejam atentos às variáveis da economia e da política, em termos locais e globais, sabendo, portanto, enxergar as oportunidades para que o negócio possa expandir não só no meio local, mas também em mercados externos. O plano de negócios, como o estudo demonstrou, prevê possíveis dificuldades inerentes à esses questionamentos, e, dessa forma, formula uma política empresarial capaz de atender a todos os fatores que conduzem a empresa a um crescimento homogêneo, e, ainda, constante. Nesse sentido, o plano financeiro é essencial ao plano de negócio, tendo como objetivo prever as necessidades monetárias da empresa.

Visa-se, dessa forma, atender certa expectativa de produção, e, também, prever as possíveis incertezas do mercado, traçar planos alternativos para que caso algo planejado não transcorra da melhor forma tenha-se uma outra estratégia, e, ainda, o plano serve para que caso os resultados caminhem para além das expectativas, tenha-se planos para conduzir a produção sem que haja prejuízo da imagem da empresa por falta de oferta do produto ou em razão da qualidade causada pela produção indiscriminada. Deve-se, então, discriminar no plano pontos relevantes e caros à gestão em seus mais diversos sentidos, para que ele possa ser aplicado de 
forma segura. Em termos financeiros o planejamento à curto prazo, o caixa, a previsão de vendas e o planejamento do lucro são essenciais e indispensáveis.

Conclui-se que o plano de negócios atua como uma ferramenta que viabiliza o planejamento da empresa como um todo, uma vez que identifica os pontos fortes da empresa que a tornarão competitiva. Realiza, também, um levantamento sobre as suas fraquezas e as vantagens das concorrentes, e, assim, o plano pode ser um fator chave para a sobrevivência ou não de uma empresa, visto que o cenário corporativo se revela cada vez mais competitivo. Nesse sentido, o artigo visou demonstrar a importância do plano de negócio para o sucesso da empresa e a versou sobre a relevância desse no âmbito do marketing e das finanças, mas ele pode ser expandido a todos os setores da empresa. É uma forma de compreender, em detalhes, o modo de funcionamento de um negócio e se ele é eficaz.

\section{REFERÊNCIAS}

BERNARDI,

Manual de plano de negócios: fundamentos, processos e estruturação. São Paulo: Atlas, 2008.

CHIAVENATO, I. Gestão de Pessoas: o novo papel dos recursos humanos nas organizações. Rio de Janeiro: Campus, 1999.

CHIAVENATO, I. Empreendedorismo: dando asas ao espírito empreendedor. São Paulo: Saraiva, 2005.

CHIAVENATO, I. Administração: teoria, processo e prática. Rio de Janeiro: Elsevier, 2007.

DORNELAS, J. C A.Empreendedorismo na prática: mitos e verdades do empreendedor de sucesso. Rio de Janeiro: Elsevier, 2007. 
FORSTER, J. de. M. Plano de marketing: Armário Ideal Ltda. 2017. 84f. Trabalho de Conclusão de Curso (Graduação em Administração) - Universidade Federal do Rio Grande do Sul, Porto Alegre, 2017.

KOTLER, P. Princípios de marketing. São Paulo: Atlas, 1998.

KOTLER, P.; ARMSTRONG, G. Princípios de marketing. São Paulo: Prentice Hall, 1998.

LEAL, C. P.; NASCIMENTO, J. A. R. do. Planejamento financeiro pessoal. Revista de Ciências Gerenciais, v. 15, n. 22, p. 163-186, 2011.

LUCION, C. E. R. Planejamento financeiro. Revista eletrônica de contabilidade, v. 2, n. 1, p. 160, 2005.

MANGINI, E. R. et al. Plano de Marketing de Serviços Aplicado a Instituição de Ensino. Revista IPTEC, v. 6, n. 2, p. 01-15, 2018.

MANNA, H. R. Plano de negócios para abertura de pizzaria na zona norte da cidade de Porto Alegre. 2011. 64f. Trabalho de Conclusão de Curso (Graduação em Administração) - Universidade Federal do Rio Grande do Sul, Porto Alegre, 2011.

OLIVEIRA, D. C. A importância do planejamento financeiro. Revista Intellectus, Ano VIII, n. 20, p. 75-83, 2012.

PINTO, C. dos. S. et al. Elaboração de um plano de negócios: relato de experiência de egressas do curso de Administração. In: 9o Salão Internacional de Ensino, Pesquisa e Extensão, 2017.

QUADROS, F. Z. Plano de negócios e a pequena empresa de base tecnológica: um estudo de caso na incubadora de empresas do Midi Florianópolis. 2004. $133 f$. Dissertação (Mestrado em Engenharia de Produção) - Universidade Federal de Santa Catarina, Florianópolis, 2004. 
SANTOS, P. V. S.; PINHEIRO, F. A. O plano de negócios como ferramenta estratégica para o empreendedor: um estudo de caso. Revista Latino-Americana de Inovação e Engenharia de Produção, v. 5, n. 8, p. 150-165, 2017.

SEBRAE. Como Elaborar Um Plano de Negócios. Brasília. 2013.

SILVA, E. C.; MAZZON, J. A. Plano de Marketing Social para a Promoção da Saúde: Desenvolvimento de Políticas de Saúde Pública Orientada ao "Cliente". Revista Brasileira de Marketing, v. 15, n. 2, p. 164-176, 2016.

ZIMMERMAN, J. Using Business Plans ForTeaching Entrepreneurship. American Journal of Business Education (AJBE), v. 5, n. 6, p. 727-742, 2012.

Enviado: Fevereiro, 2020.

Aprovado: Junho, 2020. 